Supporting Information for

\title{
Competition of Sorption and Degradation Reactions during Glyphosate Degradation by Ferrihydrite/Delta-manganese-oxide Composites
}

\author{
by \\ Hui $\mathrm{Li}^{1}$, and Deb P. Jaisi ${ }^{1 *}$ \\ ${ }^{1}$ Department of Plant and Soil Sciences, University of Delaware, Newark, DE 19716 United States \\ * Corresponding author: Deb P. Jaisi; Email: Jaisi@udel.edu; Phone: (302) 831-1376
}

Seven Pages, Six Figures 


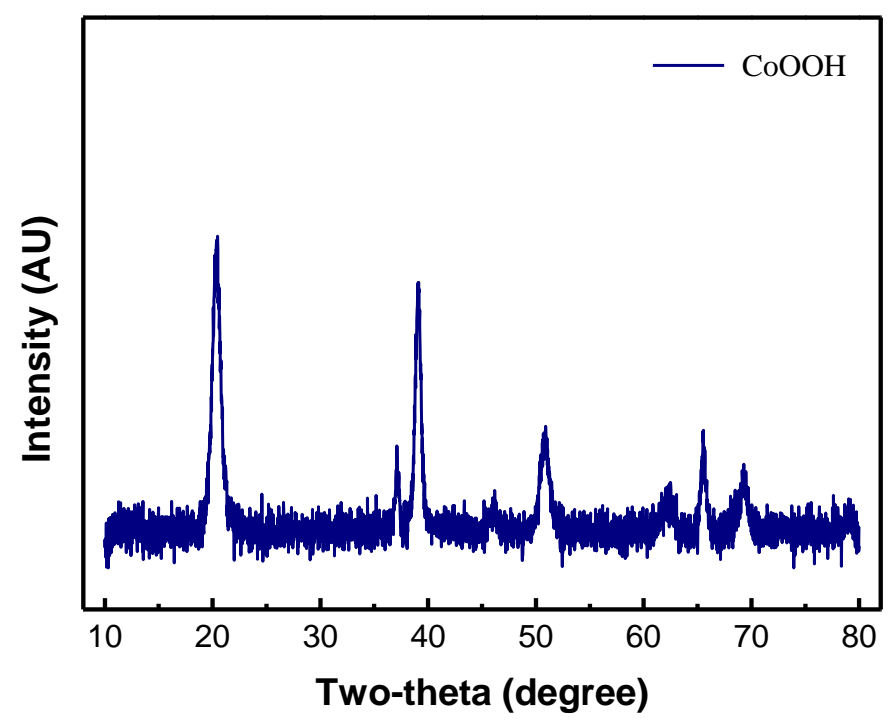

Figure S1. XRD pattern of synthetic cobalt oxyhydroxide. 
a-1) $\mathrm{Mn}: \mathrm{Fe}=1.67$
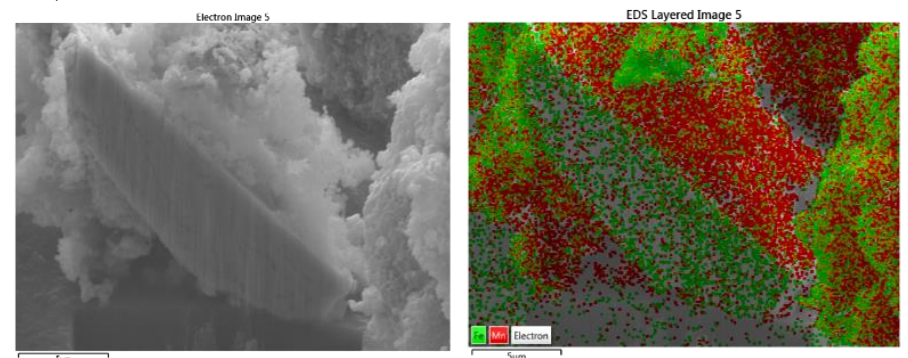

a-2) $\mathrm{Mn}: \mathrm{Fe}=1.67$
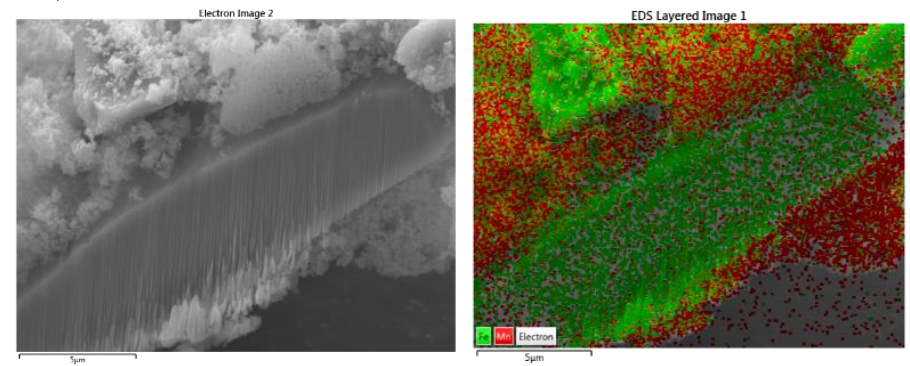

b) $\mathrm{Mn}: \mathrm{Fe}=0.167$
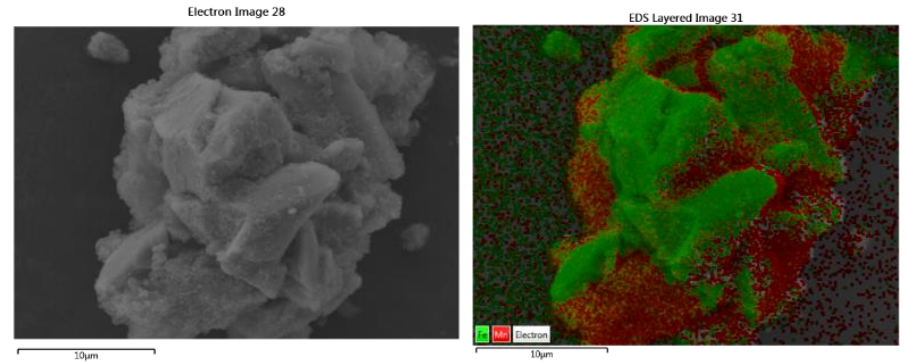

c) $\mathrm{Mn}: \mathrm{Fe}=0.0835$
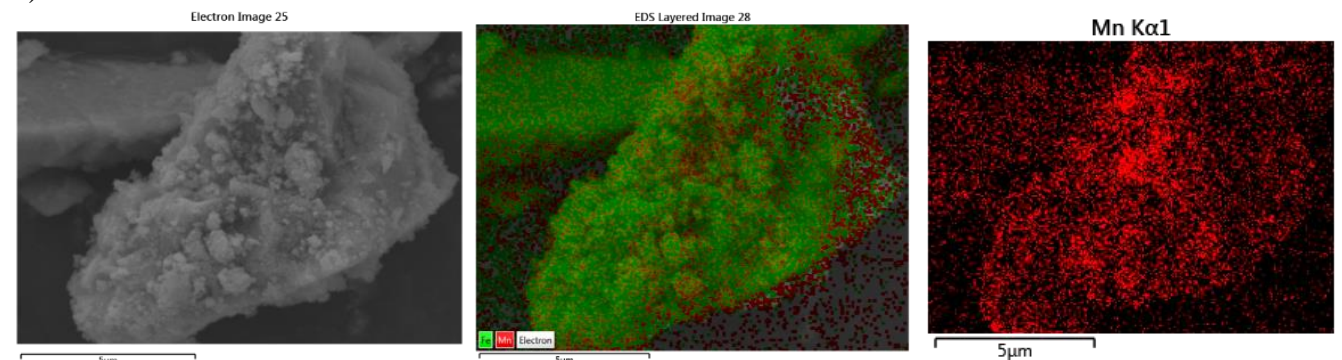

d) $\mathrm{Mn}: \mathrm{Fe}=0.0167$
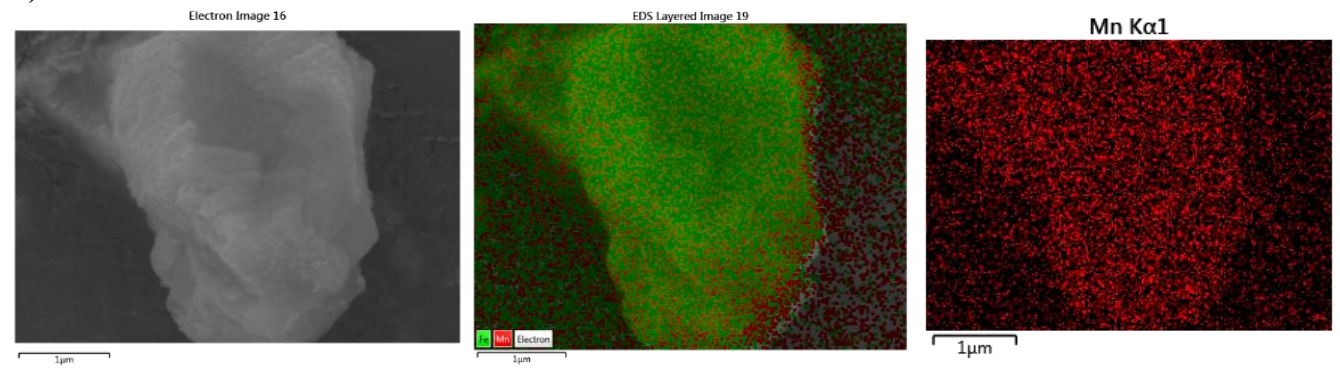

Figure S2. SEM (black and white) and EDS (color) images of synthetic ferrihydrite/ $\delta-\mathrm{MnO}_{2}$ composites with molar ratios of Mn:Fe ranging from 1.67 (a) to 0.0167 (d). 


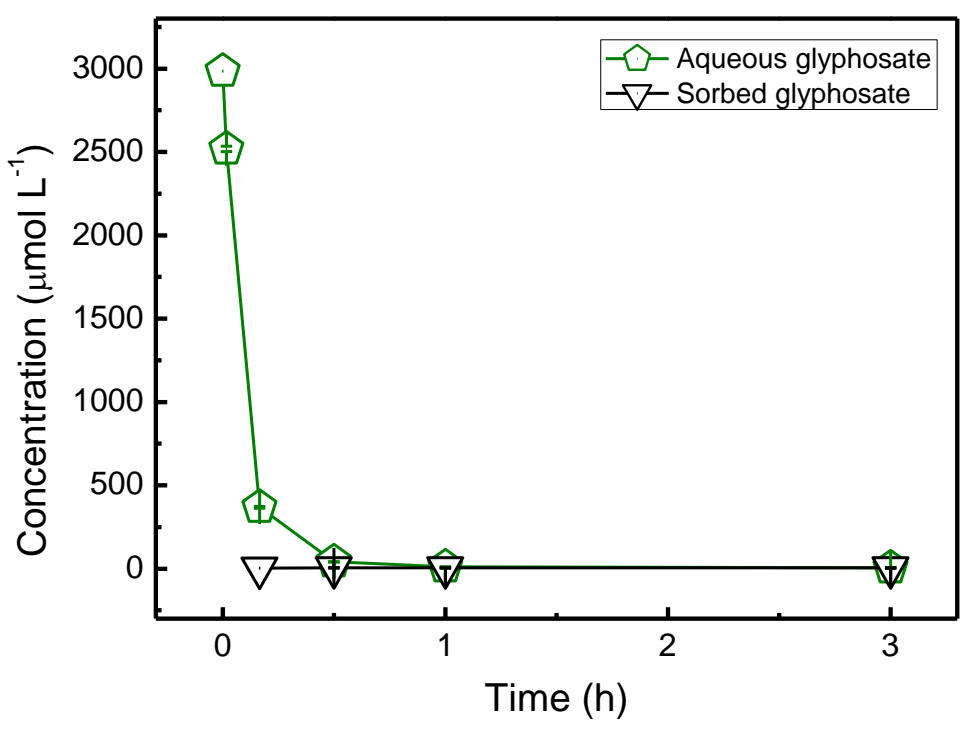

Figure S3. Kinetics of glyphosate $(3000 \mu \mathrm{mol} \mathrm{L}-1)$ degradation by $\delta-\mathrm{MnO}_{2}\left(5 \mathrm{~g} \mathrm{~L}^{-1}\right)$ measured as the unreacted glyphosate in aqueous and solid phases. 


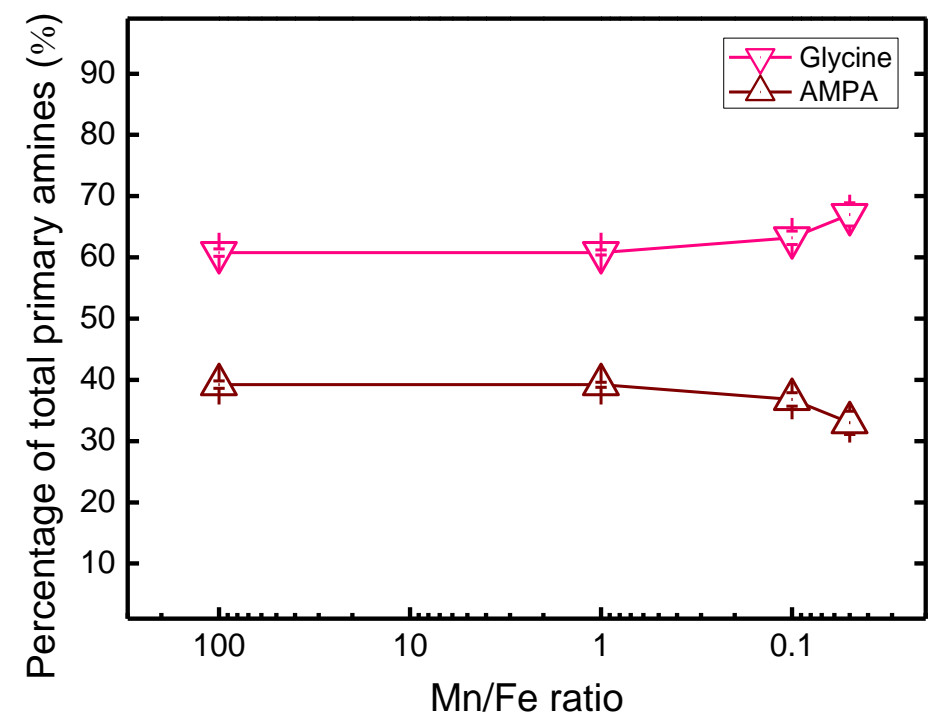

Figure S4. The relative extent of glycine or AMPA in generated primary amines during glyphosate degradation by minerals at different $\mathrm{Mn}: \mathrm{Fe}$ ratios. 


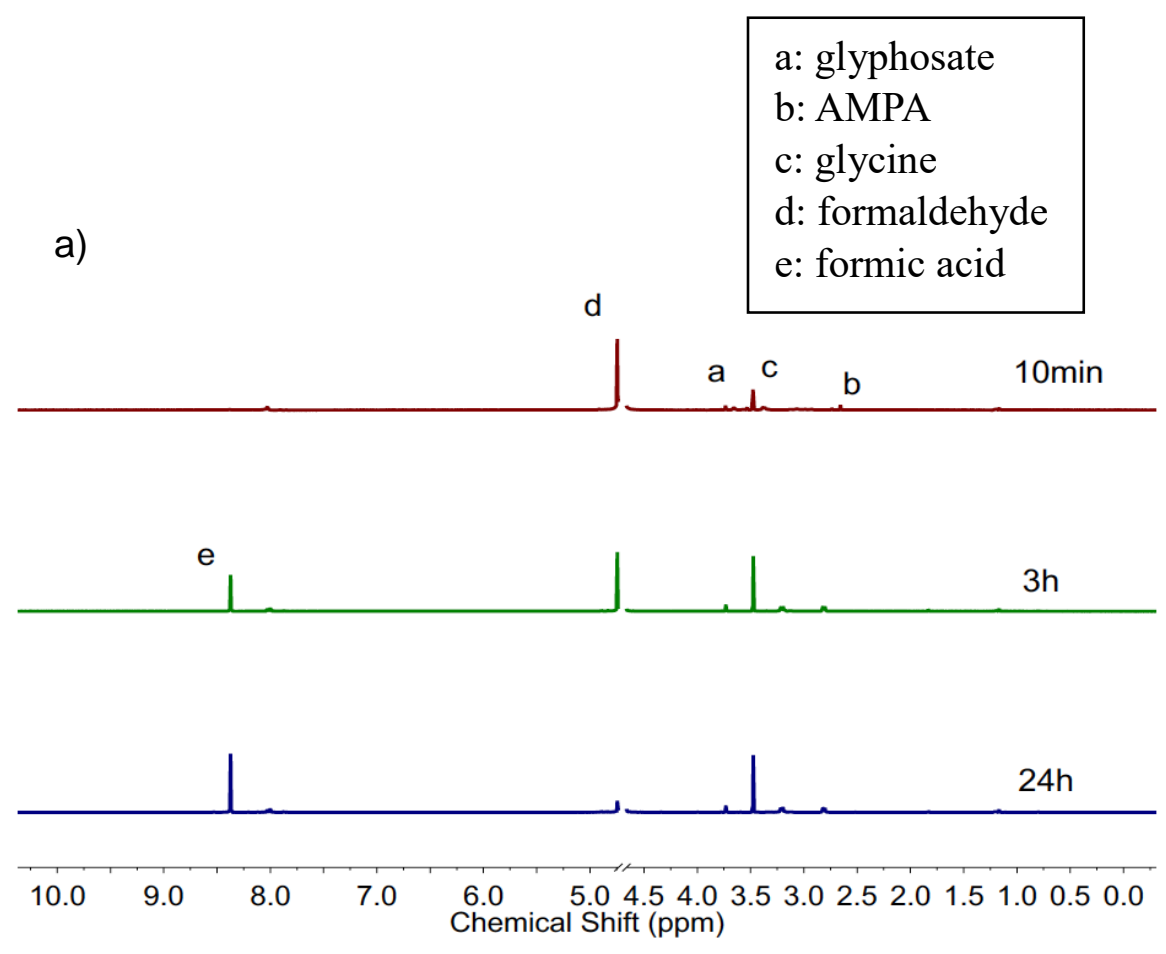

b)

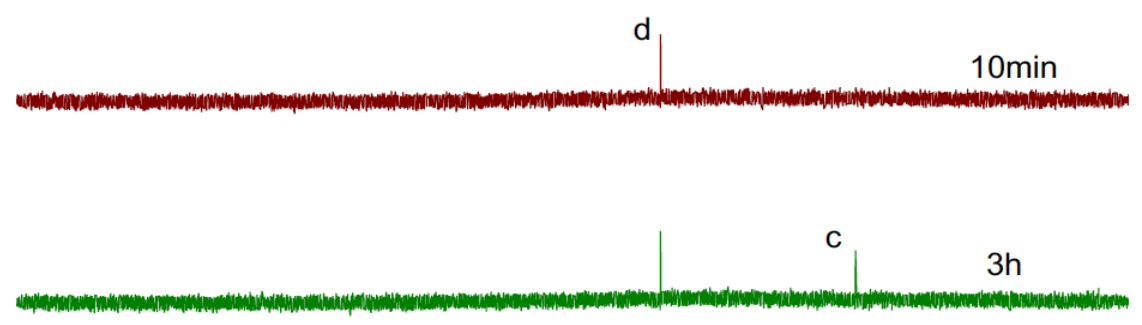

e

$24 \mathrm{~h}$

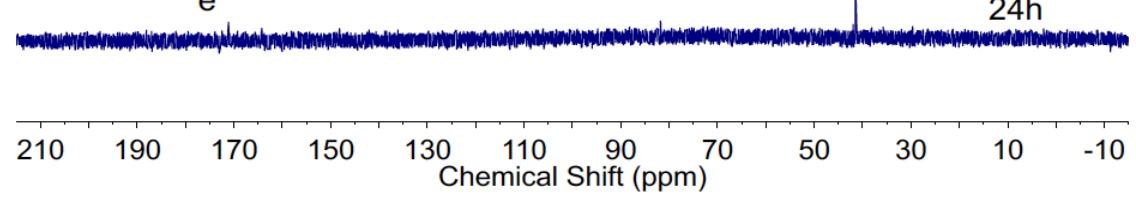

Figure S5. NMR spectra of degradation products accumulated in aqueous solutions: (a) ${ }^{1} \mathrm{H}$ and (b) ${ }^{13} \mathrm{C}$ spectra. The experiment was run with glyphosate $(3000 \mu \mathrm{mol} \mathrm{L}-1): \delta-\mathrm{MnO}_{2}\left(5 \mathrm{~g} \mathrm{~L}^{-1}\right)$ at $\mathrm{pH} 7.00( \pm 0.05)$. 


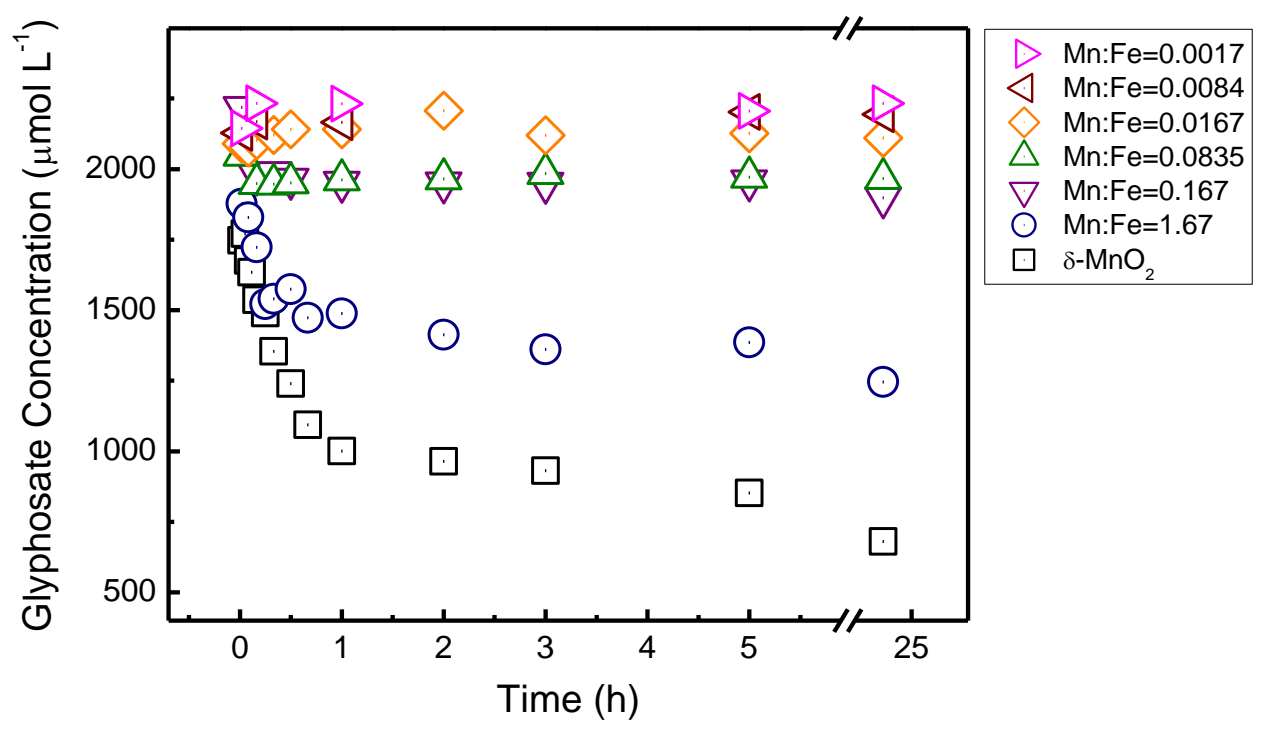

Figure S6. Kinetics of glyphosate $\left(2000 \mu \mathrm{mol} \mathrm{L} \mathrm{L}^{-1}\right)$ degradation by pure $\delta-\mathrm{MnO}_{2}$ and ferrihydrite/ $\delta-\mathrm{MnO}_{2}$ composites $\left(1 \mathrm{~g} \mathrm{~L}^{-1}\right)$ with $\mathrm{Mn}$ :Fe ratios ranging from 0.0017 to 1.67 . The concentration of glyphosate is the sum of unreacted glyphosate in aqueous and on solids. 